\title{
Improving Schoolyard Wind Environments: Case Studies in Two Schools in Nanjing
}

\author{
Anqi Liu' ${ }^{A^{*}}$, Qiuxia $\mathrm{Xu}^{\mathrm{A}}$, Jiahao $\mathrm{Gao}^{\mathrm{A}}$, Zhen $\mathrm{Xu}^{\mathrm{A}}$, Lingyun $\operatorname{Han}^{\mathrm{B}}$ \\ Received: November 26, 2019 | Revised: December 24, 2019| Accepted: December 26, 2019 \\ DOI: $10.5937 / g p 23-24183$
}

\begin{abstract}
Wind environment as an essential aspect of urban micro-climate is usually studied as an important factor affecting human wind comfort and thermal comfort in public open space. Less studied is how wind environments influence schoolyard serving for children and teenagers who are more sensitive to air temperature and air pollution. This paper presents a study using XFlow for wind speed evaluation based on CFD (Computational Fluid Dynamics) simulation, and Ecotect Analysis for thermal comfort evaluation. Choosing Nanjing Mochou Lake Primary School and Nanjing NO.13 Middle School Suojin Campus as case studies, it offers an evaluation of wind environments in these two schoolyards and surrounding open spaces. Simulation shows that improvements should be made to build better wind environments around both schools. Scenarios are developed subsequently by adjusting buildings in study areas at the scale of blocks and school buildings, proving the efficiency of improvements for a more comfortable wind environments. This study focuses on schoolyard wind environments from the standpoint of children and teenagers, suggesting that research on urban micro-climate can be expanded in multiple directions so that as many social groups in different ages as possible benefits, i.e. have healthier urban life.
\end{abstract}

Keywords: schoolyard wind environment; CFD simulation; public open space; urban micro-climate

\section{Introduction}

Consideration of climatic factors in urban design can trace back to around 2000 years ago, Vitruvius (BC 32-22) argued that, in his classic The Ten Books on Architecture, urban form and architectural layout can be influenced by different climatic conditions. The phenomenon of Urban Heat Island (UHI) was observed for the first time in 1818 by Howard. After that, more and more researchers have been aware of the significance of urban micro-climate research and doing the research from different perspectives. Oke (1973) analyzed large amount of measured data in relation to UHI, concluding that with favourable ventilation, urban air circulation can be promoted, air pollution can be eliminated greatly and problem of UHI can even be solved. From then on, wind environments involving wind comfort and thermal comfort has become a research stream receiving much attention in multiple studies. In terms of urban form, Oke (1988) found that the ratio of canyon walls height and canyon width $(\mathrm{H} / \mathrm{W})$ along with sky view factor (SVF) have effects on urban wind environments. Ubota et al. (2008) identified the decrease of wind speed at pedestrian level as the density of buildings increases. Applying automatic algorithms to accurately assess non-stationary outdoor thermal comfort in urban areas, Bajsanski et al. (2015) predicted that the building height and density

\footnotetext{
A Nanjing Forestry University, 159 Longpan Road, Nanjing, China, 210037; 183709417@qq.com, xuqiuxia@njfu.edu.cn, 2191139668@qq.com, xuzhen@njfu.edu.cn

B Jiangsu Second Normal University, Nanjing, China, 210037; hly0202@126.com

* Corresponding author: Zhen Xu, e-mail: xuzhen@njfu.edu.cn, telephone: +8613705171465, 00862585427090
} 
increases in the future street design will influence thermal comfort. Likewise, Milosevic et al. (2017) showed that the location of trees in street parking lots as well as tree crown shapes are important for the improvement of outdoor thermal comfort and should be considered during the urban planning process. Without regard to surrounding open spaces and architectural layout, Du et al. (2018) performed wind environments simulation of 3 different heights of an isolated building and a group of buildings respectively, discovering wind comfort at pedestrian level is positively correlated with height. In terms of building form, Gao et al. (2012) conducted a year-long simultaneous field measurements at University of Reading campus in the UK, measured data showed that building form is the key factor effecting resulting airflow. Furthermore, Yuan et al. (2012) compared different building forms of influences on ventilation at pedestrian level, stepped building was highlighted as conducive to wind environments. As to other artifacts, Bajsanski et al. (2017) proposed an approach for windbreak fence design based on a bionic parametric model of the shark skin denticle geometry and this new kind of windbreak fence proved to effectively reduce wind speed can be utilized to improve wind conditions in open and urban spaces. Based on these findings, wind environment can be thought as an essential aspect of urban micro-climate and is usually studied as an important factor affecting human wind comfort and thermal comfort in public open space. There are also macro and micro attempts to change the speed and direction of wind in order to improve wind environments. However, less studied is how wind environments influence schoolyard as well as what improvements can be proposed to enhance schoolyard performance.

As one of the core area for outdoor public activities, it is easy to gather large population in schoolyard serving for children and teenagers. For this sub-population, due to younger age, they are more vulnerable to the negative effects of extreme temperature and air pollution which can be eased by suitable wind environments. The main difference between school buildings and other public buildings is the semi-closed architectural layout in school, here largely referring to primary school and middle school. Most schools in China are gated with walls which also results in poor ventilation. Earlier research on schoolyard thermal environment found that playground characterized by a hardscape surface has higher temperature than which in surrounding open spaces (Moogk-soulis, 2002). Using Envi-met simulation, Antoniadis et al. (2018) identified that vegetated roof and shading canopies can improve micro-climate in schoolyard. However, both of them paid no attention to wind speed in their studies. Gan et al. (2019) analyzed 3 kinds of school building forms influencing specific spots around apart from overall wind environment within schoolyard. Therefore, research on wind environments in outdoor activity spaces within schoolyard is in an early stage and, as a matter of course, improvements focusing on schoolyard wind environments are almost in blank.

With high efficiency, precision and low cost, CFD (Computational Fluid Dynamics) technique has been utilized in multiple fields. This paper presents a study using XFlow for wind speed evaluation based on CFD simulation, and Ecotect Analysis for thermal comfort evaluation. Choosing Nanjing Mochou Lake Primary School and Nanjing NO.13 Middle School Suojin Campus as case studies, it offers an evaluation of wind environments containing wind comfort and thermal comfort in these two schools and surrounding open spaces. Simulation shows that improvements are required to create better wind environments within both schoolyards. Scenarios are developed subsequently by adjusting buildings in study area at the scale of blocks and school buildings, proving the efficiency of improvements for a more comfortable wind environments. Finally, implications are made for future schoolyard environments investigation, planning and design.

\section{Data and methods}

\section{Location}

The case study areas are located in two schools and surrounding area in Nanjing, China, locational relationship is shown in Figure 1. These two schools are Nanjing Mochou Lake Primary School and Nanjing NO.13 Middle School Suojin Campus, respectively. Using modeling standard of AIJ (Architecture Institute of Japan), surrounding area includes at least one block expended in each direction from the school.

Mochou Lake Primary School with approximately 700 students covers an area of $16036 \mathrm{~m}^{2}$. The school- yard is located near the main road of the city. Where the terrain is relatively flat with big difference of building height around school. NO.13 Middle School Suojin Campus with 1591 students covers an area of around $20000 \mathrm{~m}^{2}$. This area is located in Suojin Community with a little topographic relief. Spatial form surrounding schoolyard is complex while the height of buildings is almost equal.

Building and city road network data is acquired from government and subsequently modeled in AutoCAD and SketchUp. Building outlines are simplified, 

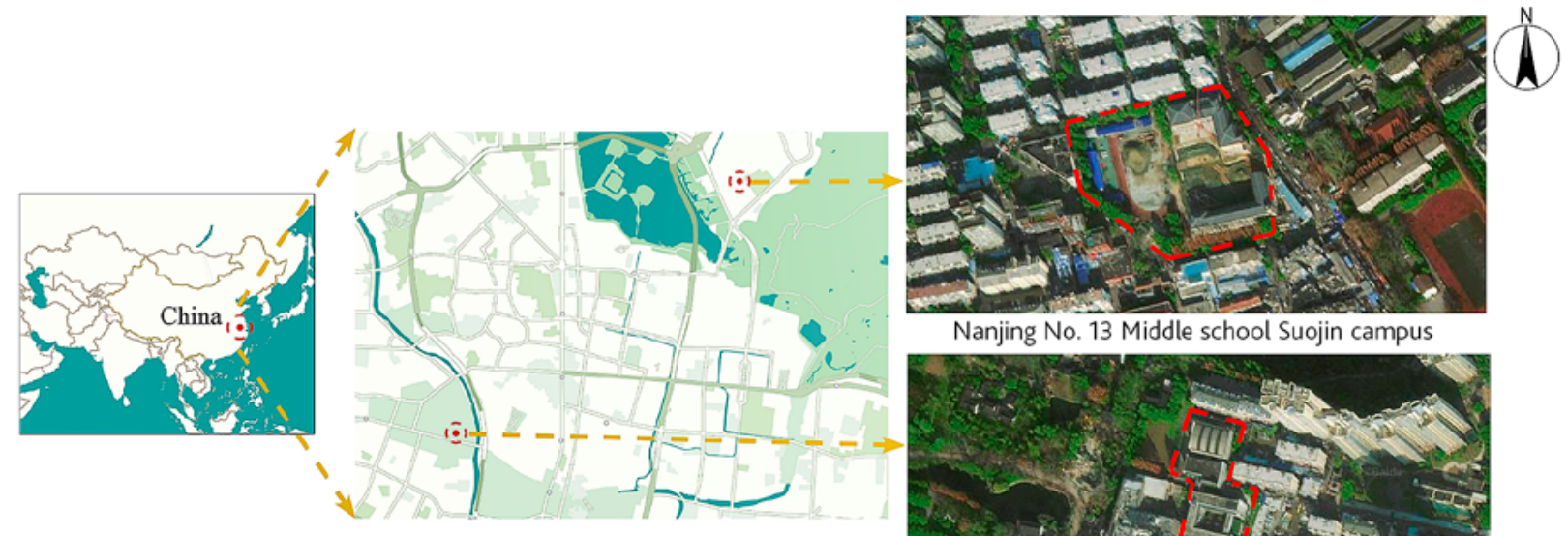

Nanjing No. 13 Middle school Suojin campus

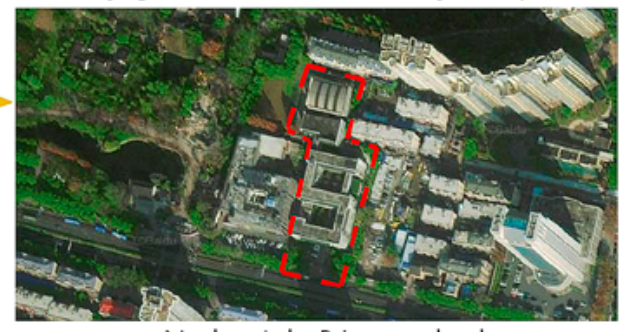

Mochou Lake Primary school

Figure 1. Locational relationship between two schools

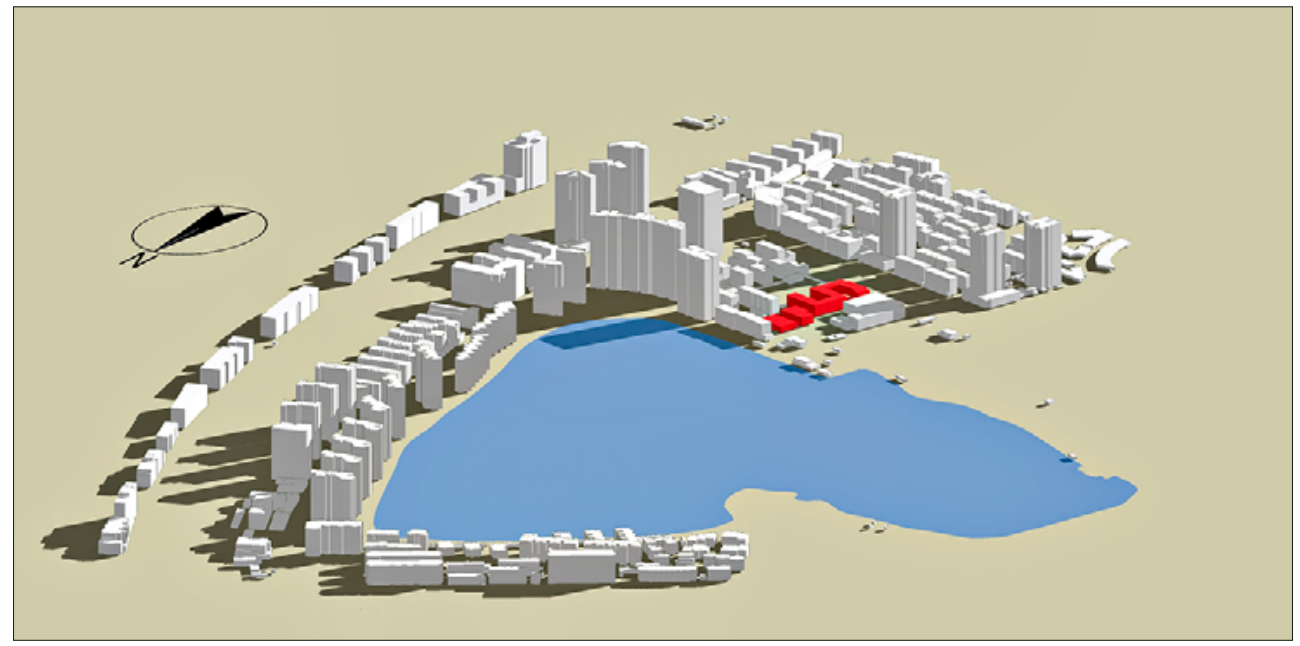

Figure 2. Model of Mochou Lake Primary School and surrounding open spaces including at least one block expended in each direction, school buildings are shown in red

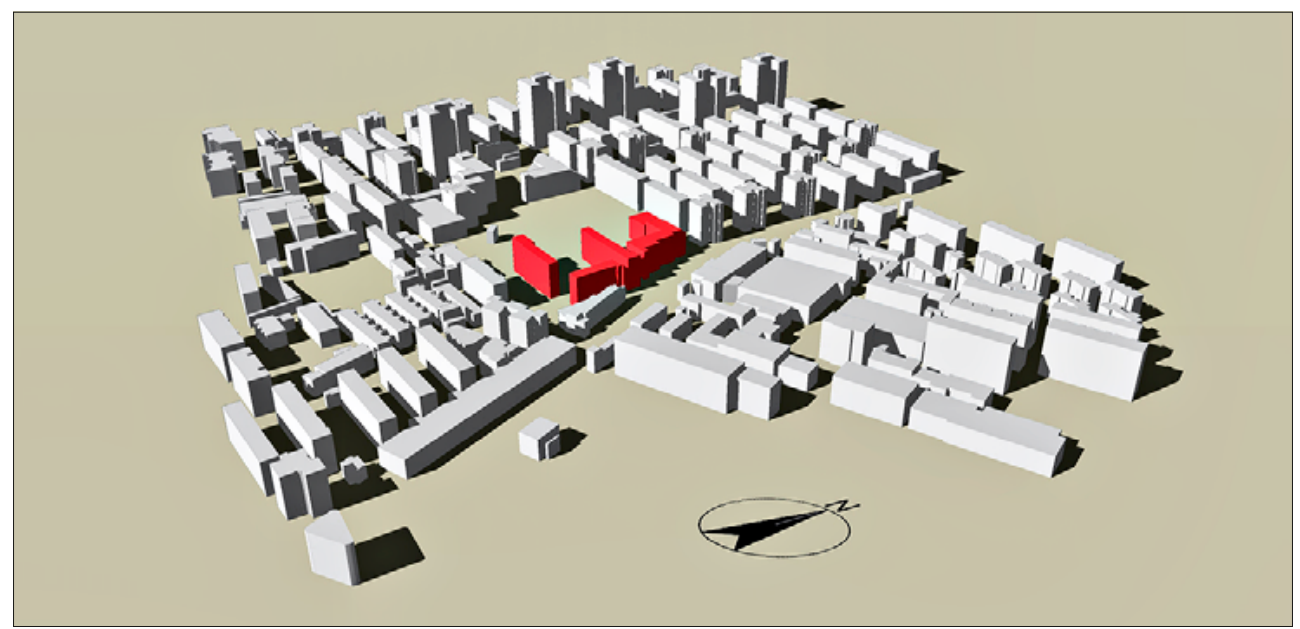

Figure 3. Model of NO.13 Middle School Suojin Campus and surrounding open spaces including at least one block expended in each direction, school buildings are shown in red 
with vegetation and small artifacts left out. Because of almost flat terrain, the influence of terrain on airflow can be negligible. The models of these two study areas are shown in Figure 2 and Figure 3.

\section{Wind environments simulation}

Based on CFD technique, XFlow as a software devoted to fluid flow simulation is utilized in this study to simulate, predict and analyze wind field. Wind environments considering the wind over two schools are reproduced in XFlow. Besides, air temperature is simulated in Ecotect Analysis, which is a software with comprehensive functions for a greater energy performance of buildings. With limited computer capability, it requires that calculating area would better not be too large. Thus, taking school as the center, area of $500 \mathrm{~m}^{\star} 500 \mathrm{~m}$ is cut out as the study area for thermal comfort evaluation.

Chinese Standard Weather Data coming from the US Department of Energy (DOE) is collected as the meteorological data in this study. Considering that summer and winter are two typical seasons with less comfort for outdoor activities in Nanjing, this two seasons are chosen in wind environments simulation. Selecting predominate wind direction in June, July and August as wind direction parameter in summer, it identifies that the approaching wind direction used for simulation is SSE (south-southeast), with average wind speed and average temperature around $2.8 \mathrm{~m} / \mathrm{s}$ and $26.3{ }^{\circ} \mathrm{C}$ respectively. Accordingly, selecting predominate wind direction in December, January and February as wind direction parameter in winter, it identifies that the approaching wind direction is ENE (east-northeast), with average wind speed and average temperature around $3.0 \mathrm{~m} / \mathrm{s}$ and $3.8^{\circ} \mathrm{C}$ respectively.

\section{Thermal comfort evaluation criteria}

Since there is no standard evaluation criteria characterizing the thermal comfort in different climate zones at present in China, and considering the climate features in Nanjing-hot in summer and cold in winter, the author uses different criteria to characterize thermal comfort respectively.

In summer, wind speed is one of the main factors influencing human thermal comfort in Nanjing with temperature and humidity are both high. It has been proved that temperature and wind speed have significant effects on human thermal comfort especially for younger people, whose skin surface area is much smaller and relies more on wind instead of evaporative heat loss. For every $1{ }^{\circ} \mathrm{C}$ rise in air temperature, the wind speed should be increased by $0.5 \mathrm{~m} / \mathrm{s}$ (Khedari et al., 2000). Wu et al. (2012) established the thermal comfort evaluation table in Hong Kong, classifying wind speed into 5 categories at pedestrian level in summer: a) calm $-\mathrm{V}<0.3 \mathrm{~m} / \mathrm{s}$; b) terrible$0.3 \mathrm{~m} / \mathrm{s} \leq \mathrm{V}<0.6 \mathrm{~m} / \mathrm{s} ;$ c) not good- $0.6 \mathrm{~m} / \mathrm{s} \leq \mathrm{V}<1.0 \mathrm{~m} / \mathrm{s}$; d) $\operatorname{good}-1.0 \mathrm{~m} / \mathrm{s} \leq \mathrm{V}<1.3 \mathrm{~m} / \mathrm{s}$; e) excellent $-V \geq 1.3 \mathrm{~m} / \mathrm{s}$. Given that the temperature in Nanjing and Hong Kong are with high similarity in summer (Figure 4), the 'thermal comfort evaluation criteria of summer at pedestrian level in Nanjing' (Table 1) is established referring to the thermal comfort evaluation table in Hong Kong.

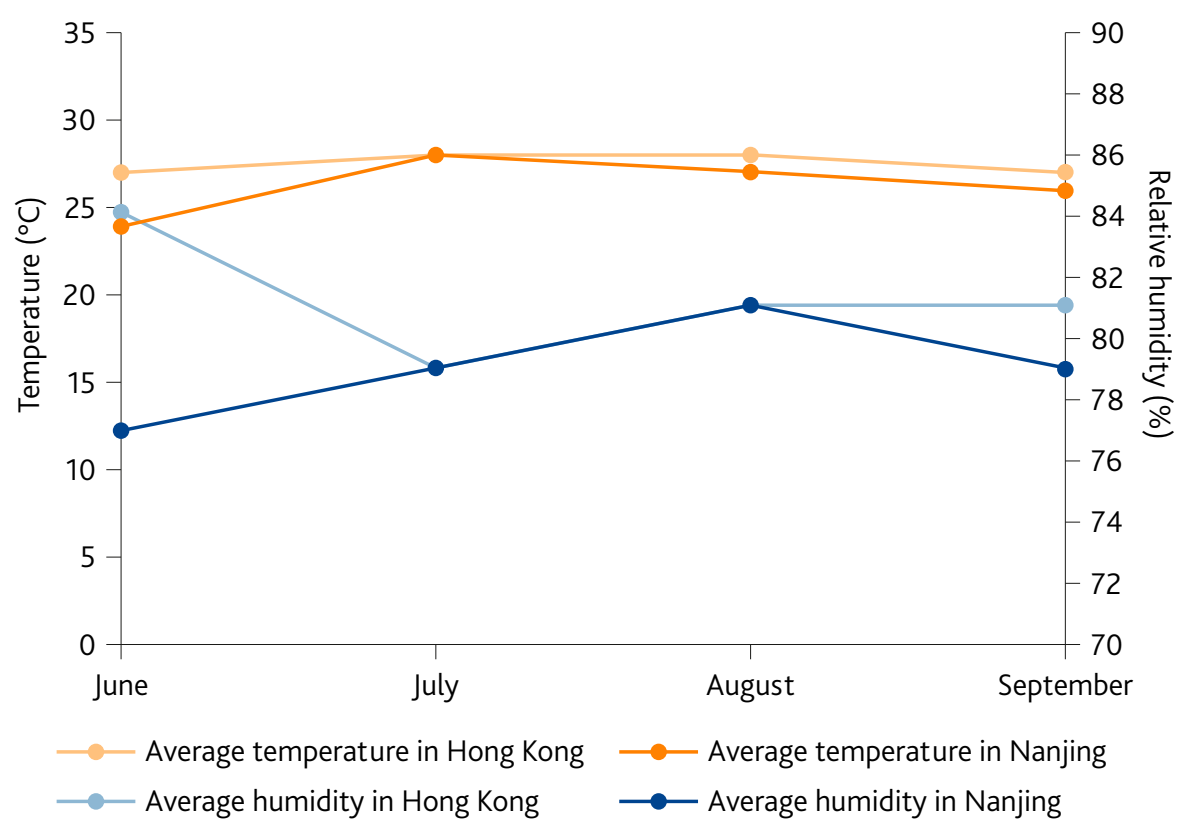

Figure 4. Comparison of climate in summer between Nanjing and Hong Kong Source: Yang et al., "Coupling Mechanism Between Thermal Environment and Space Form and Optimization Design in City Center", adapted by author 
In winter, wind with high speed will deteriorate the cold feeling of people outdoors. Therefore, windproof environment becomes the most important requirement of urban wind environment in winter. Using wind effect index $(\mathrm{K})$ reflecting the effect for wind speed and temperature on human body as well as heat exchange between human body and environment, with positive value standing for heat absorption while negative value standing for heat dissipation. The $\mathrm{K}$ value can be calculated in the following equation:

$$
K=-(10 \sqrt{V}+10.45-V)(33-T)+8.55 S
$$

Where, $V$ stands for environmental wind speed $(\mathrm{m} / \mathrm{s}), T$ represents Celsius $\left({ }^{\circ} \mathrm{C}\right), S$ is the sunshine duration in one day $(\mathrm{h} / \mathrm{d})$. Citing $K$ value as a criterion, the evaluation criteria of thermal comfort in winter are shown in Table 2. In addition, wind speed in winter should be no less than $1 \mathrm{~m} / \mathrm{s}$ in order to promote elimination of air pollution.
Table 1. Thermal comfort evaluation criteria in summer at pedestrian level in Nanjing.

\begin{tabular}{|c|l|c|}
\hline Wind speed & Feelings & Evaluation \\
\hline $\mathrm{V}<0.3$ & $\begin{array}{l}\text { No wind with terrible thermal } \\
\text { comfort }\end{array}$ & 1 \\
\hline $0.3 \leq \mathrm{V}<0.6$ & $\begin{array}{l}\text { Unbearable with poor thermal } \\
\text { comfort }\end{array}$ & 3 \\
\hline $0.6 \leq \mathrm{V}<1.0$ & Tolerant & 5 \\
\hline $1.0 \leq \mathrm{V}<1.3$ & Somewhat satisfied & 7 \\
\hline $\mathrm{V} \geq 1.3$ & Comfortable & 9 \\
\hline
\end{tabular}

Source: Wu et al. (2008), "Urban Climatic Map and Standards for Wind Environment: Feasibility Study", adapted by author

Table 2. Thermal comfort evaluation criteria in winter at pedestrian level in Nanjing.

\begin{tabular}{|c|l|c|}
\hline Range of K value & Feelings & Evaluation \\
\hline $\mathrm{K} \leq-1200$ & Freezing cold & 1 \\
\hline$-1200<\mathrm{K} \leq-1000$ & Frosty & 3 \\
\hline$-1000<\mathrm{K} \leq-800$ & Cold & 5 \\
\hline$-800<\mathrm{K} \leq-600$ & Cool & 7 \\
\hline$-600<\mathrm{K} \leq-300$ & Comfortable & 9 \\
\hline
\end{tabular}

Source: the author

\section{Results}

Schoolyard wind environments, which is a research stream with less popularity in broadly defined urban micro-climate, is paid a lot of attention here. Wind speed distributions in study areas are generated in XFlow based on CFD technique, and then thermal comfort distributions are calculated through Ecotect Analysis. Case study of two schools has been analyzed specifically and the results of wind comfort and thermal comfort are presented in this section.

\section{Wind comfort and thermal comfort of two schoolyards in summer}

As shown in Figure 5, it can be seen that schoolyard of Mochou Lake Primary School is generally in calm zone (no wind), while wind speed in Shuiximen Street near the schoolyard is up to around $2 \mathrm{~m} / \mathrm{s}$, which means that ventilation in this street is in a favourable situation. This can be accounted for by the fact that Shuiximen Street as a main road in city has the effect of wind corridor, however, the wall of school and surrounding artifacts on the east side of schoolyard form a nearly enclosed space which blocks the entry of wind along the street. The thermal comfort distribution of Mochou Lake Primary School schoolyard is shown in Figure 6, which corresponds to the wind comfort analysis mentioned above. It can be seen that, in a similar vein, ther- mal comfort in schoolyard is relatively poor in summer even though Shuiximen Street is in a good situation. Thus, it can be concluded that good ventilation in broad roads can not necessarily bring about better wind comfort and thermal comfort for surrounding open spaces, i.e. the schoolyard, if architectural layout near the road is too compact and there are artifacts, such as walls, cutting off the flow of wind.

As shown in Figure 7, it can be seen that NO.13 Middle School Suojin Campus does somewhat better, although wind speed in schoolyard is still in a low level. Moreover, community roads outside the school also have a high level of wind comfort, but the wind speed here is around $1.5 \mathrm{~m} / \mathrm{s}$, a little smaller than that in Shuiximen Street, which probably due to narrower width. In spite of this, the looser layout of buildings here brings schoolyard more possibilities of ventilation. The thermal comfort distribution of NO.13 Middle School Suojin Campus is shown in Figure 8. It can be seen that better ventilation with more accessible architectural layout results in higher level of thermal comfort. However, the semi-closure of school buildings leading to a stuffy condition is not conducive to local thermal comfort. Thus, it can be concluded that configuration of school buildings matters as important as architectural layout surrounding school. 


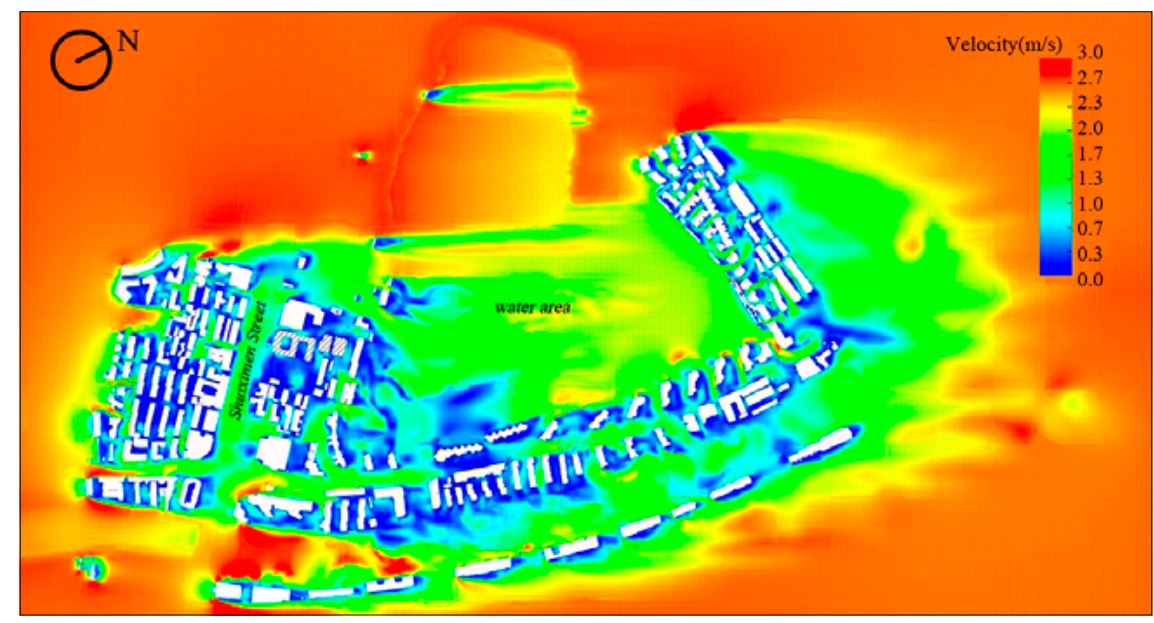

Figure 5. Wind speed distribution in summer in Mochou Lake Primary School and surrounding open spaces. School buildings are shaded (the same below), with the main road in city besides. The wind speed varies from low to high corresponding to the colour varies from blue to red (the same below)

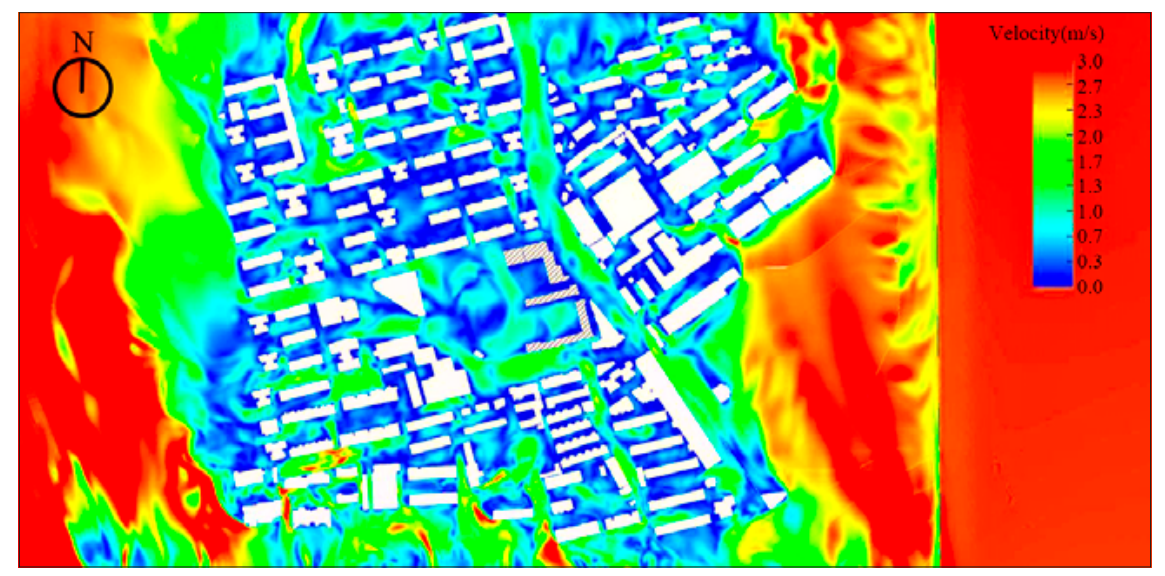

Figure 7. Wind speed distribution in summer in NO.13 Middle School Suojin Campus and surrounding open spaces

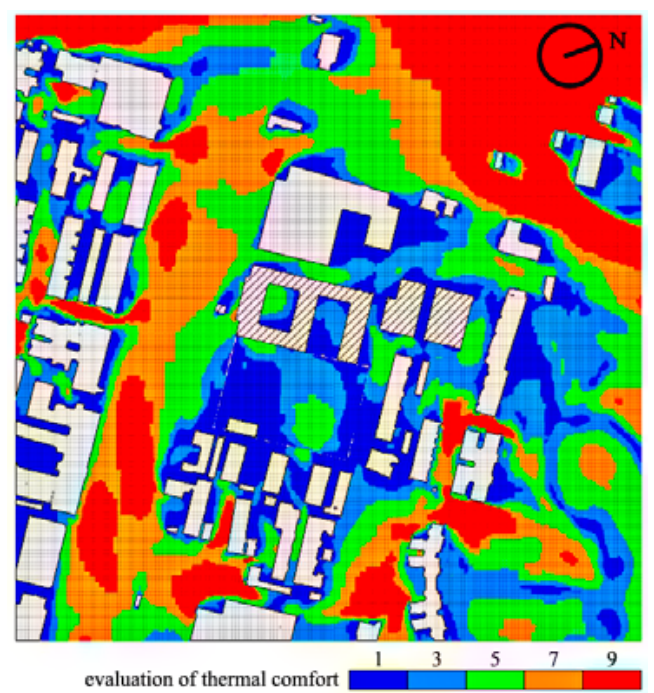

Figure 6. Thermal comfort distribution in summer in Mochou Lake Primary School and surrounding open spaces. The degree of comfort varies from low to high corresponding to the colour varies from blue to red (the

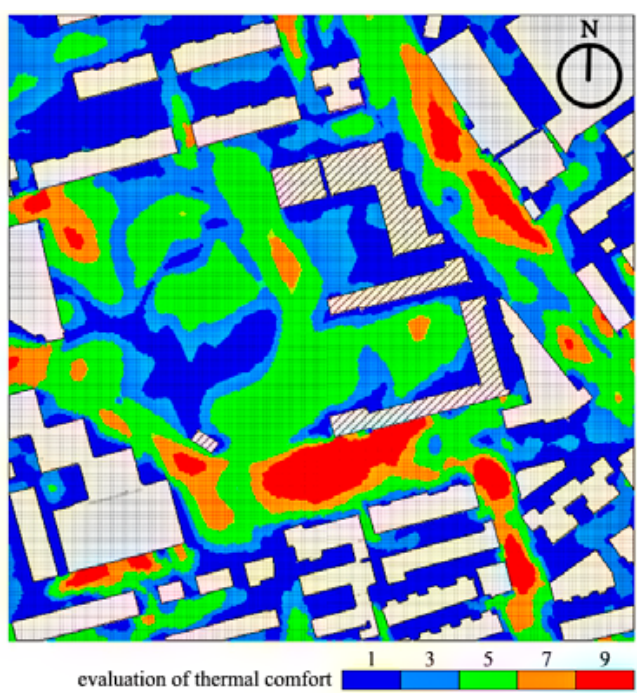

Figure 8. Thermal comfort distribution in summer in NO.13 Middle School Suojin Campus and surrounding open spaces 


\section{Wind comfort and thermal comfort of two campuses in winter}

As shown in Figure 9 and Figure 10, the ventilation in these two schoolyards in winter is similar to it in summer, which means that windproof environments have been built in order to prevent heat dissipation. Figure 11 and Figure 12 are thermal comfort distributions within these two schoolyards, conforming to wind speed distributions, it reveals the fact that ther- mal comfort within both schoolyards is at high level and outdoor activities probably will not be disturbed by cold wind in winter. But the problem comes to the air condition in school. Poor ventilation keeping warm in winter is not favour of eliminating air pollution which may cause respiratory diseases. Thus, it can be concluded that improvement of wind environments in winter should focus on promoting air circulation within schoolyard.

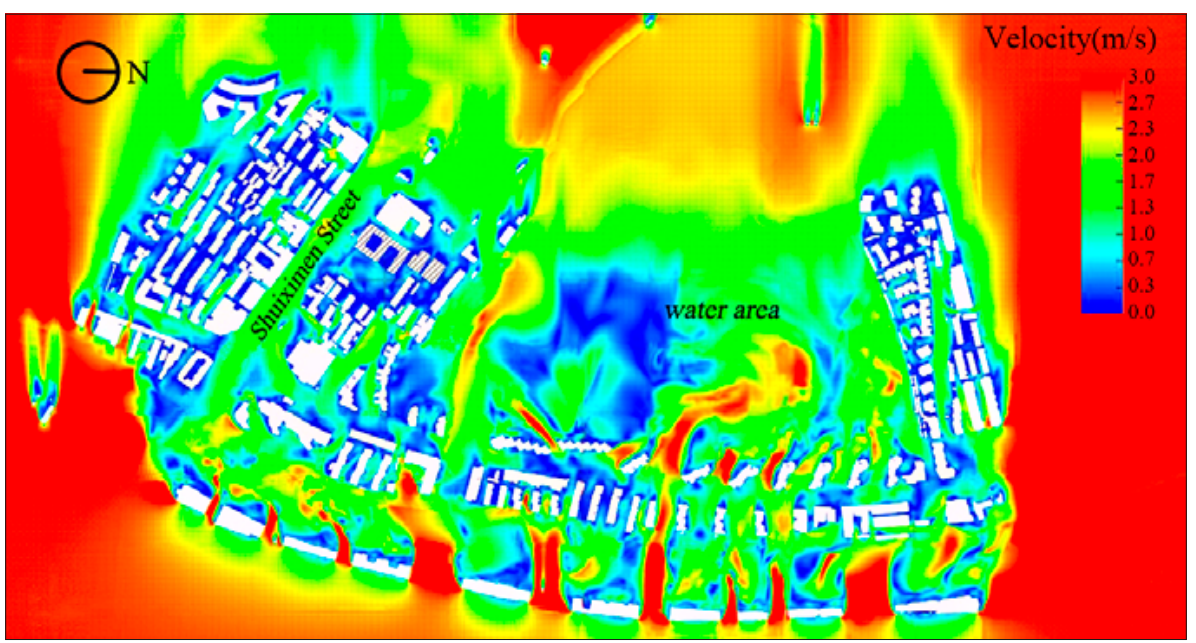

Figure 9. Wind speed distribution in winter in Mochou Lake Primary School and surrounding open spaces

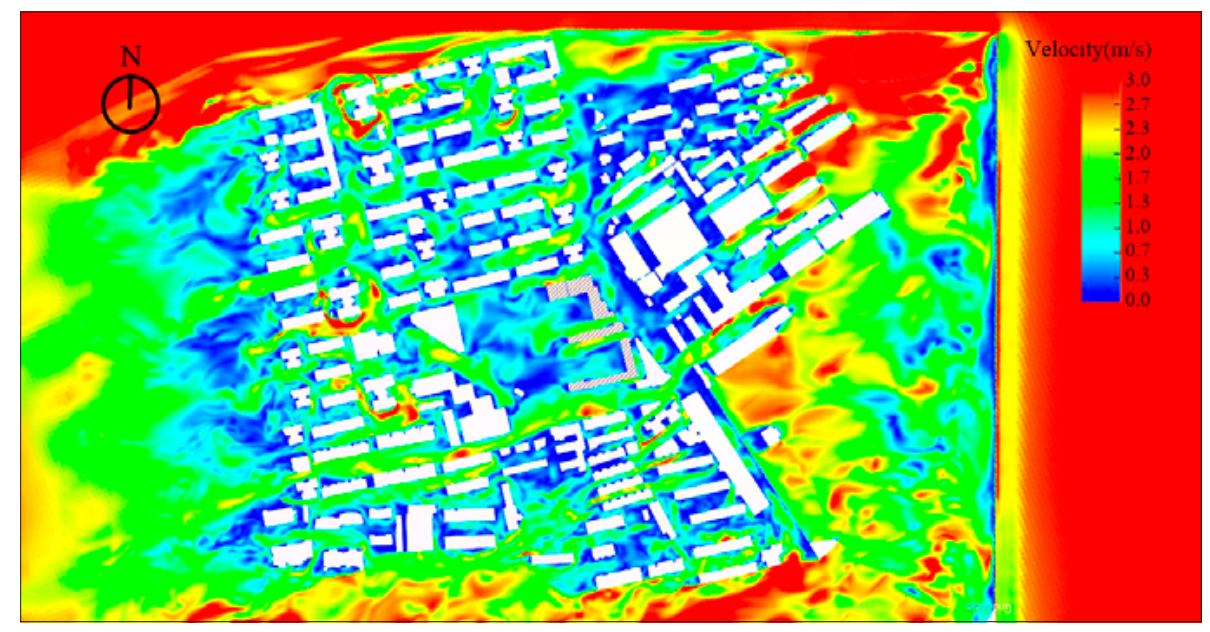

Figure 10. Wind speed distribution in winter in NO.13 Middle School Suojin Campus and surrounding open spaces 


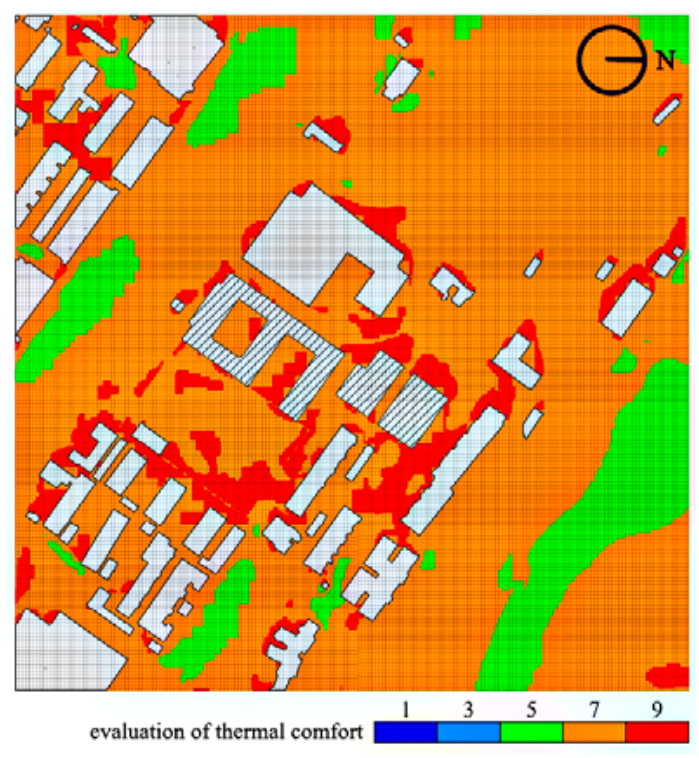

Figure 11. Thermal comfort distribution in winter in Mochou Lake Primary School and surrounding open spaces

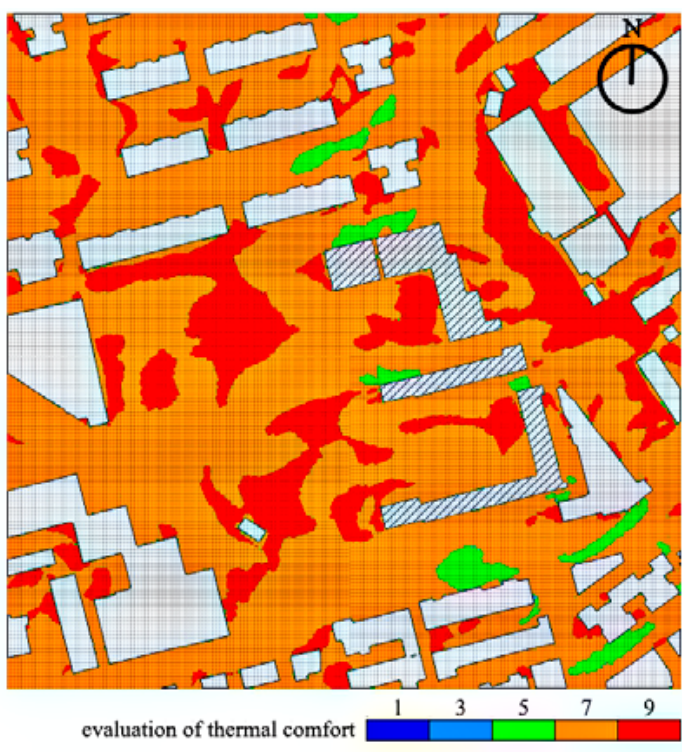

Figure 12. Thermal comfort distribution in winter in NO.13 Middle School Suojin Campus and surrounding open spaces

\section{Conclusion}

Simulation encompassing wind speed and air temperature in two cases have been analyzed in former section. Necessary for more objective understanding of thermal comfort in local environments, two different evaluation criteria have been used to distinguish between summer and winter. The resulting evaluation identifies that overall wind environments in both cases can and should be better.

Specifically speaking, wind speed in both schoolyards and in both seasons even almost in calm is at a low level. As a result, these two schools are in a poor situation no matter for wind comfort or thermal comfort in summer. When it comes to winter, thermal comfort becomes the main factor to consider and it is found that this index achieves the goal of a windproof environment within schoolyard. However, from the standpoint of health, poor ventilation means aggregated air pollution, which also means more possibilities of respiratory diseases. In general, wind speed ought to be increased appropriately on the premise of suitable thermal comfort. Therefore, specific improvements for acquiring better wind environments, within existing realities and constraints, are proposed.

\section{How to improve?}

At the scale of blocks, considering wind speed and wind direction, two scenarios with wind corridors in case of Mochou Lake Primary School are developed in different seasons, as shown in Figure 13. Since the school is near the main road-Shuiximen Street, just as analyses in former section, and the wind environ- ments in this street proved to be much better than which within surrounding schoolyard. The key point of improvement should be introducing wind along the street into schoolyard. In this way, the street can be made good use of and the potential of ventilation within schoolyard will be inspired as well. According to existing built configuration, the wall on the east side of school is the main reason of preventing the entry of wind. Thus, as shown in Figure 14, demolishing the wall and decreasing the density of buildings surrounding school by removing several buildings in idle or are in little use can make sense for better ventilation. Similarly, two scenarios with wind corridors in case of NO.13 Middle School Suojin Campus are developed following the same principle, as shown in Figure 15. The buildings being demolished are presented in Figure 16.

At the scale of school buildings, features of building like building scale, building form and building orientation all have effects on wind environment around. Given that school buildings in both cases with high degree of enclosure hinder the circulation of air within schoolyards, if outdoor activity spaces can be opened up, the unfavorable wind comfort should be greatly improved. As a result, there are some changes should be made on the form of buildings, such as liftup on the ground floor and hollow-out on the wall, as shown in Figure 17. In this way, air circulation within schoolyard can be accordingly improved as the wind coming into the schoolyard due to adjustment at the scale of blocks. 

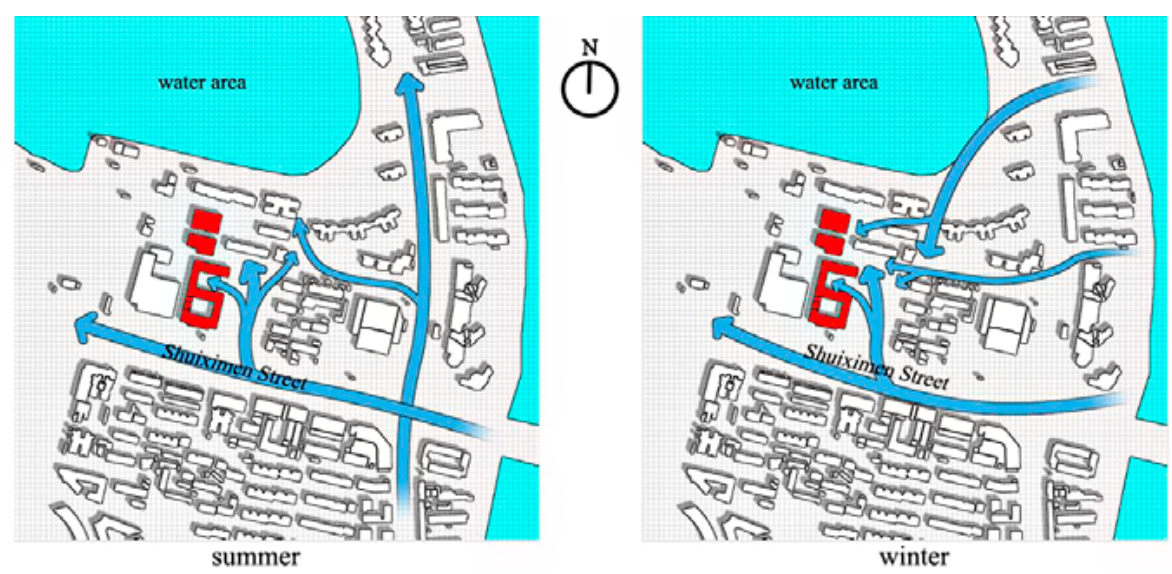

Figure 13. Two scenarios with wind corridors in case of Mochou Lake Primary School are developed in different seasons. School buildings are shown in red (the same below)
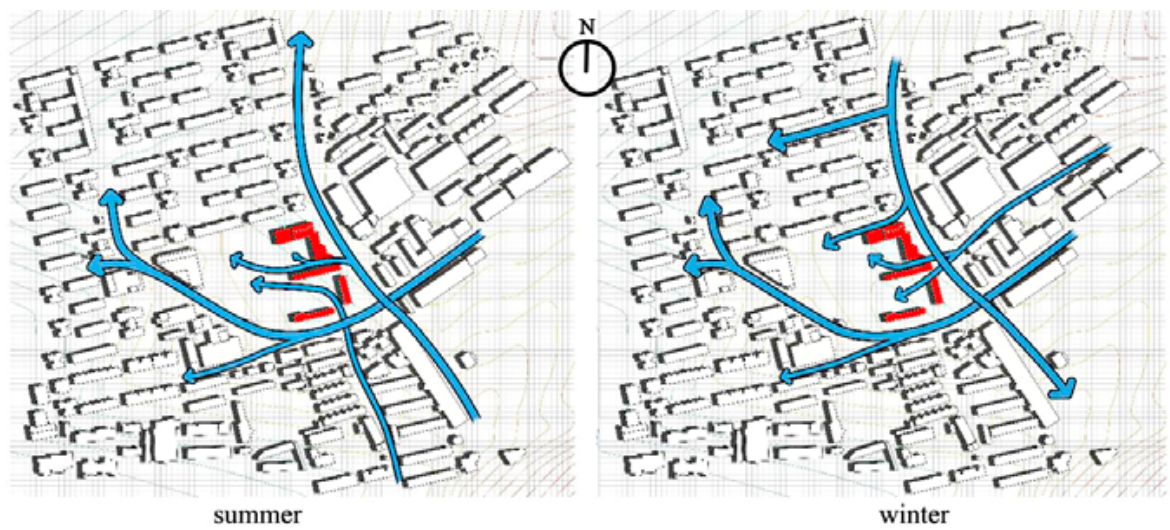

Figure 15. Two scenarios with wind corridors in case of NO.13 Middle School Suojin Campus are developed in different seasons

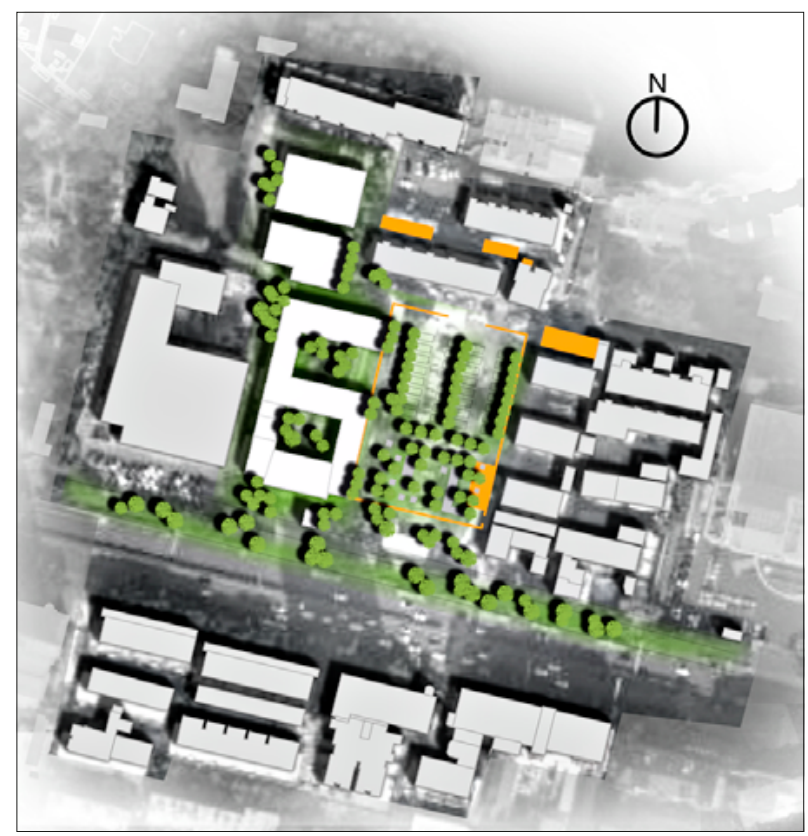

Figure 14. Improvements in case of Mochou Lake Primary School, demolished artifacts are shown in orange

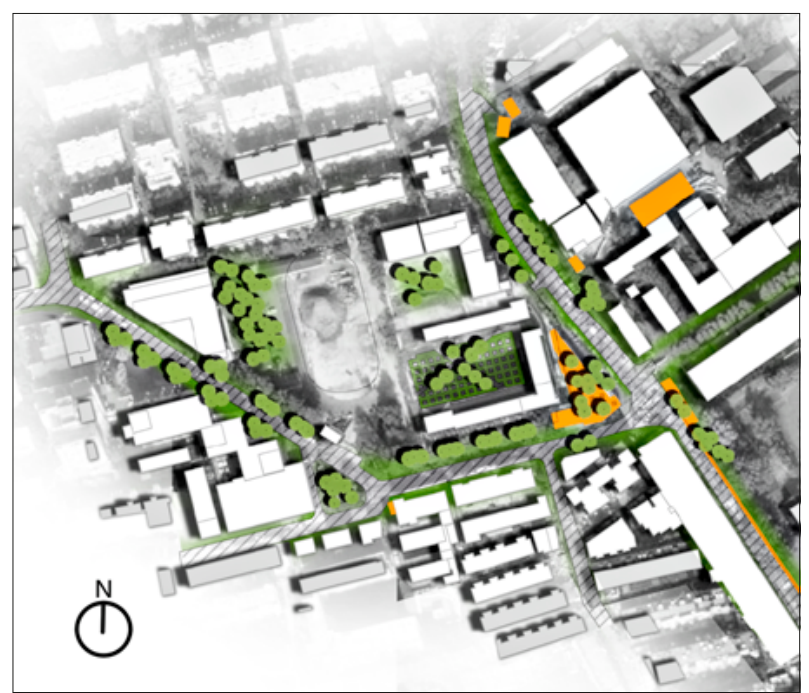

Figure 16. Improvements in case of NO.13 Middle School Suojin Campus, demolished artifacts are shown in orange 

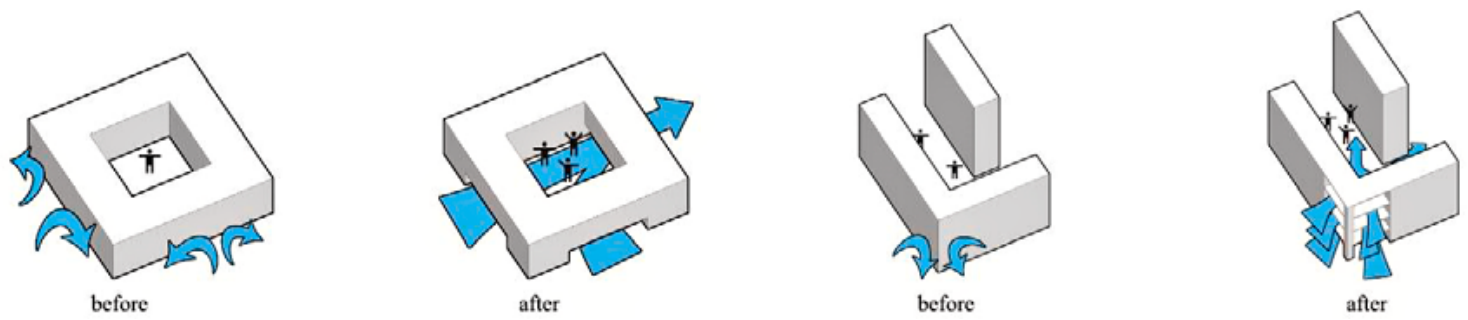

Figure 17. Improvements at the scale of school buildings, conceptual figures are shown for two different methods

\section{What happens after the improvements?}

The models improved are imported in XFlow and Ecotect Analysis in order to evaluate the efficiency of improvements, the methods are the same as which used in Section 'data and methods'.

Improved wind speed distributions of two cases in summer are presented in Figure 18 and Figure 19 respectively. It is obvious that, comparing to previous wind speed distributions, overall wind speed in schoolyards and surrounding open spaces are relatively increased, and the thermal comfort in study area is subsequently improved in summer as the ventilation promotes. As shown in Figure 20 and Figure 21, the level of thermal comfort in Mochou Lake Primary School is raised in evidence, which contributes to the result that a large range of open spaces within schoolyard heavily favour outdoor activity. At the same time, surrounding open spaces also have a better thermal comfort.

Since the main problem of schoolyard wind environments in winter is poor ventilation, the improvements should focus on increasing wind speed properly

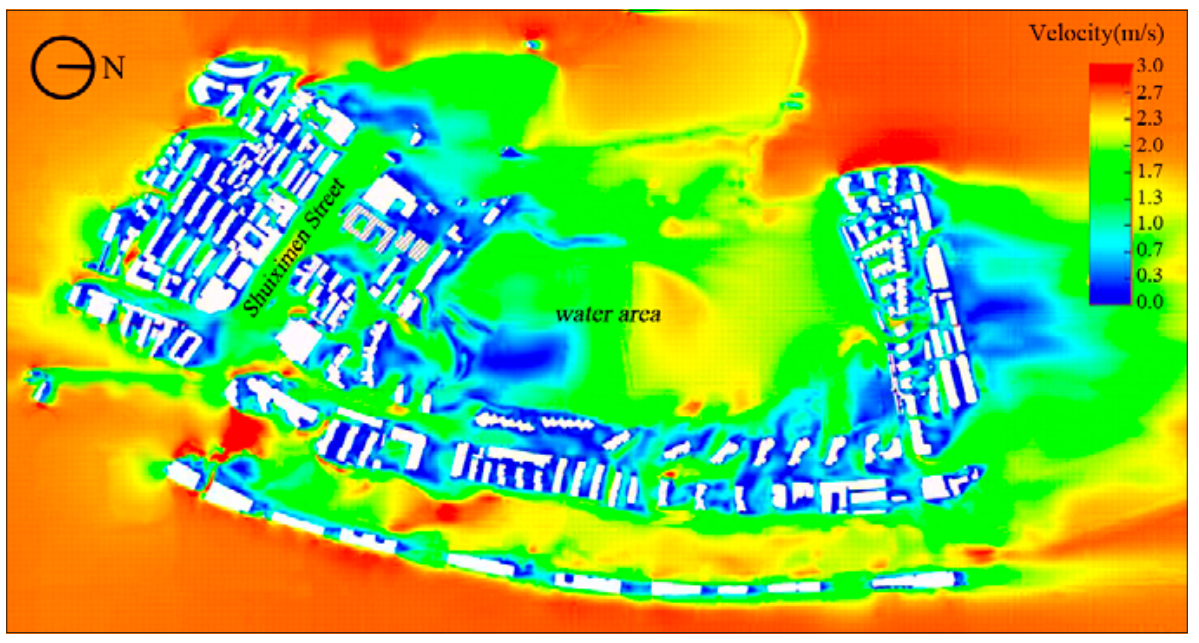

Figure 18. Improved wind speed distribution in summer in Mochou Lake Primary School and surrounding open spaces

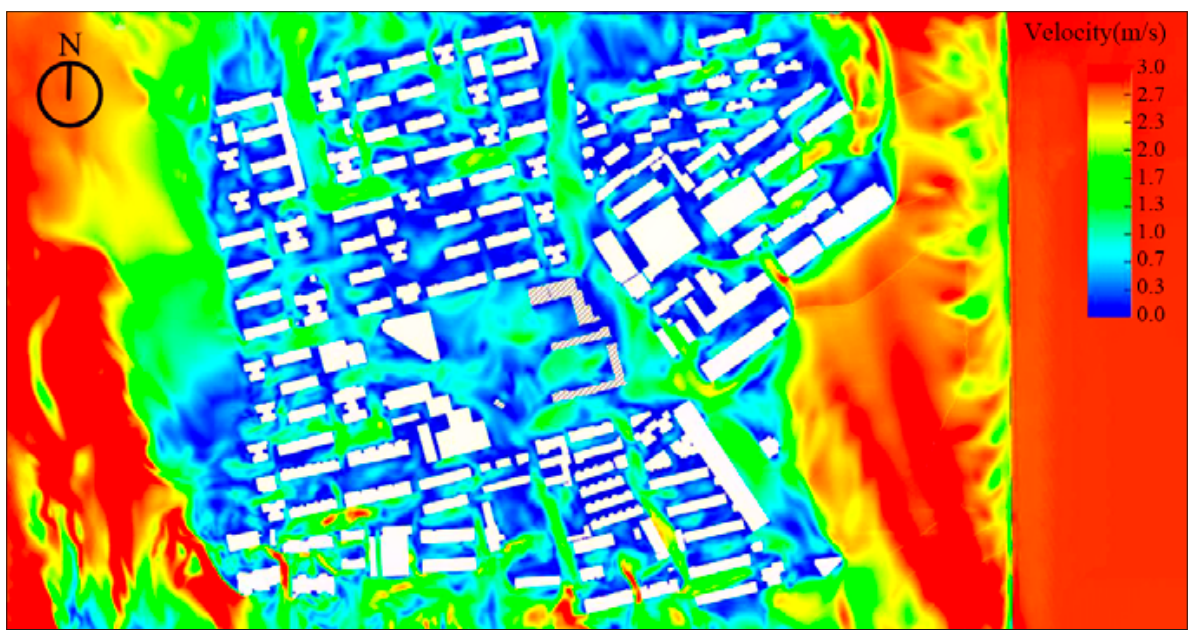

Figure 19. Improved wind speed distribution in summer in NO.13 Middle School Suojin Campus and surrounding open spaces 


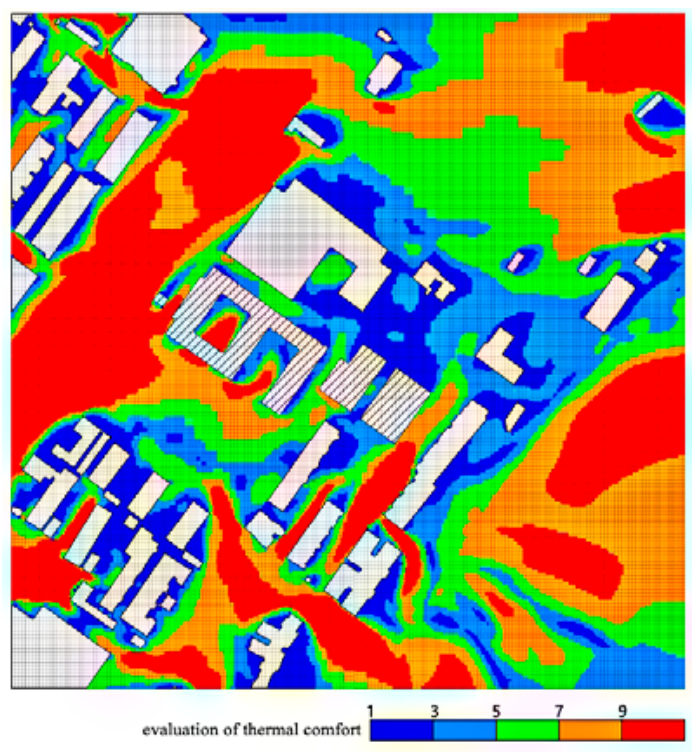

Figure 20. Improved thermal comfort distribution in summer in Mochou Lake Primary School and surrounding open spaces

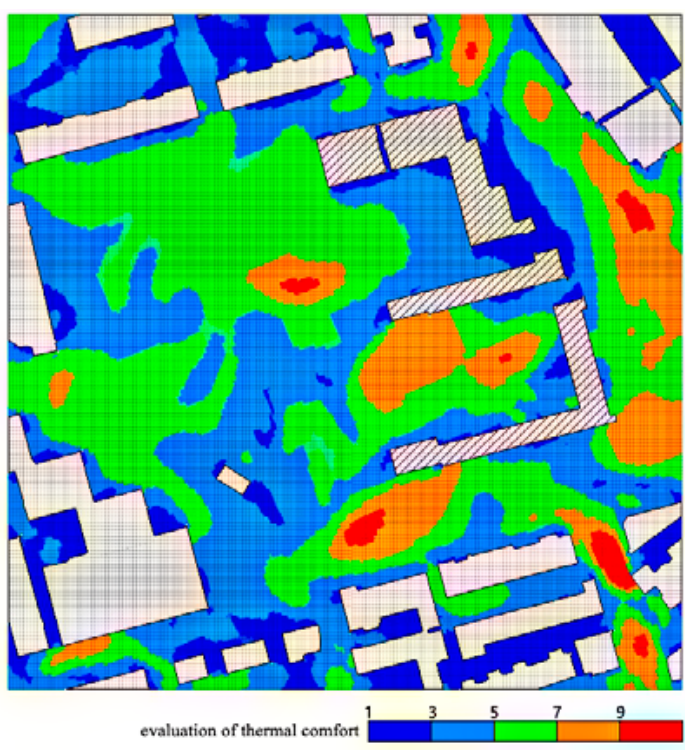

Figure 21. Improved thermal comfort distribution in summer in NO.13 Middle School Suojin Campus and surrounding open spaces

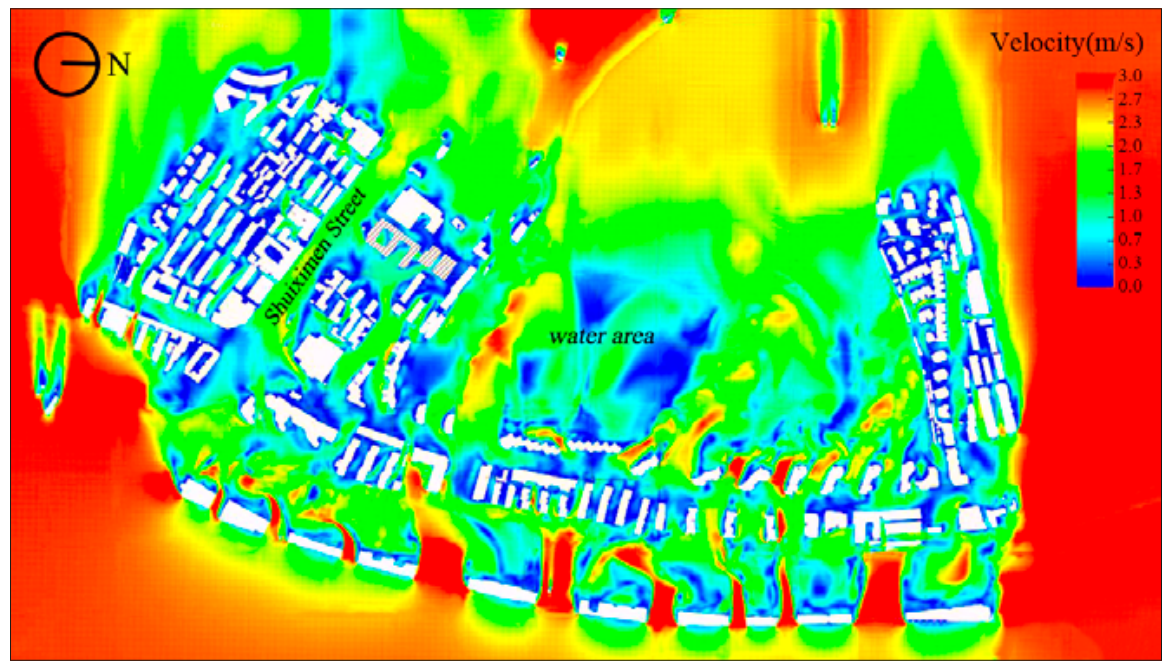

Figure 22. Improved wind speed distribution in winter in Mochou Lake Primary School and surrounding open spaces

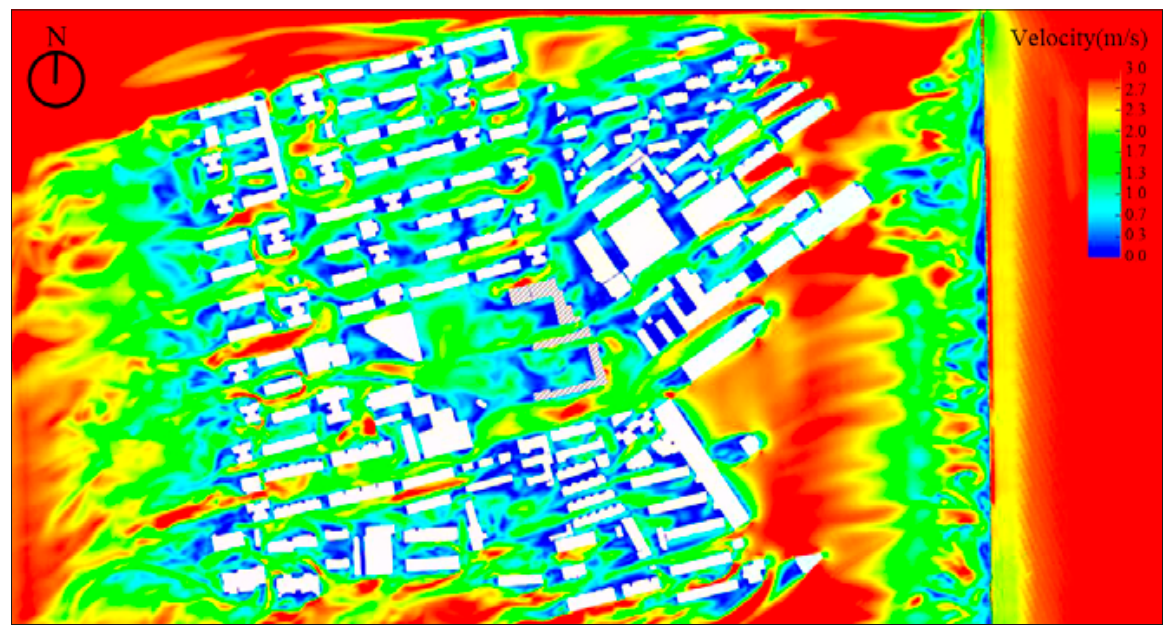

Figure 23. Improved wind speed distribution in winter in NO.13 Middle School Suojin Campus and surrounding open spaces 
within schoolyard. Improved wind speed distributions of two cases in winter are shown in Figure 22 and Figure 23. It can be seen that wind speed in both schoolyards and surrounding open spaces has been increased. Average wind speed in Mochou Lake Primary School has been increased to $1.1 \mathrm{~m} / \mathrm{s}$, and which in NO.13 Middle School Suojin Campus has been in- creased to $1.2 \mathrm{~m} / \mathrm{s}$, comparing to large range of calm zone in these two schoolyards before improvements. Besides, the wind speed increased not only improves ventilation promoting elimination of air pollution, but also satisfies the criterion of wind speed no more than $2 \mathrm{~m} / \mathrm{s}$ in winter, which ensures a moderate environment for outdoor activities.

\section{Discussion}

This study focuses on schoolyard wind environments from the standpoint of children and teenagers that has not been paid enough attention to for extended periods. The XFlow software based on CFD technique and Ecotect Analysis for thermal comfort evaluation are utilized for quantitatively evaluating wind comfort and thermal comfort in study area. Resulting analyses show that wind environments in both schoolyards and surrounding open spaces have room for improvements. Thus, appropriate adjustments at the scale of blocks and school buildings are made for changing wind over the schools and the air circulation within the schoolyards. Finally, scenarios developed after improvements are analyzed, proving efficiency of improvements for a more comfortable wind environments.

However, due to equipment limitations, elements at landscape level, such as vegetation and vertical greening which may influence energy performance of buildings, are not considered in wind speed simulation and thermal comfort evaluation. Even though urban spatial form as a high-priority aspect of wind environments, which in compact cities are influenced by many other aspects including urban climate, landscape and thermal environments. In this study, prevention of plant cover on wind and effects of shade cast by trees on air temperature are overpassed, and the influences of water area surrounding Mochou Lake Primary School on airflow and local tempera- ture are ignored as well. Besides, urban architectural layouts surrounding schools can not be well represented by only two cases. All of which constitute the limitations here. Thus, further works conducted to focus on schoolyard wind environments will incorporate elements of landscape in the models, despite which will be more complex and the calculation will be of more difficulties. The selection of study area can include as many distinct architectural layouts as possible so that schoolyard wind environments affected by different surrounding urban form can be improved in numerous ways.

In spite of limitations presented above, this paper addresses the question that schoolyard wind environments received little attention before, contributing to a deeper understanding of children and teenagers' growth environments, what's more, their health. The findings in this study, how to efficiently import wind along the road into compact architectural layouts and how to encourage air circulation within schoolyard, also provide practical significance for future schoolyard environments investigation, planning and design. Suggesting that research on urban microclimate can be expanded specifically in multiple directions including public building complex and open spaces with dense population, such as school, hospital and urban park, so that as many social groups in different ages as possible benefits, i.e. have healthier urban life.

\section{References}

Antoniadis, D., Katsoulas, N., \& Kittas, C. (2018). Simulation of schoolyard's microclimate and human thermal comfort under Mediterranean climate conditions: effects of trees and green structures. International Journal of Biometeorology, 62(11), 20252036. DOI: 10.1007/soo484-018-1612-5

Bajsanski, I., Stojakovic, V., Tepavcevic, B., Jovanovic, M., \& Mitov, D. (2017). An application of the shark skin denticle geometry for windbreak fence design and fabrication. Journal of Bionic Engineering, 14(3), 579-587. DOI: 10.1016/S1672-6529(16)60423-7
Bajsanski, I. V., Milosevic, D. D., \& Savic, S. M. (2015). Evaluation and improvement of outdoor thermal comfort in urban areas on extreme temperature days: Applications of automatic algorithms. Building and Environment, 94, 632-643. DOI: 10.1016/j. buildenv.2015.10.019

Du, Y. X., Mak, C. M., \& Tang, B. (2018). Effects of building height and porosity on pedestrian level wind comfort in a high-density urban built environment. Building Simulation, 11(6), 1215-1228. DOI: 10.1007/s12273-018-0451-y 
Falk, B. (1998). Effects of thermal stress during rest and exercise in the paediatric population. Sports Medicine, 25(4), 221-240. DOI: 10.2165/00007256199825040-00002

Gan, T. P., Ying, X. Y., \& Shen, J. Y. (2019). 基于风环境 优化的小学校园布局形态设计[The Planning Strategies of Primary School Campus Based on Wind Environment Optimization]. Architecture \& Culture, 181(4), 110-111. DOI: CNKI:SUN:JZYW.0.2019-04-032

Gao, Y. F., Yao, R. M., Li, B. Z., Turkbeyler, E., Luo, Q., \& Short, A. (2012). Field studies on the effect of built forms on urban wind environments. Renewable Energy, 46, 148-154. DOI: 10.1016/j.renene.2012.03.005

Howard, L. (2012). The climate of London: Deduced from meteorological observations. Oxford: Cambridge University Press.

Hong Kong Planning Department. (2008). Urban Climatic Map and Standards for Wind Environment: Feasibility Study.

Islam, T., Gauderman, W. J., Berhane, K., McConnell, R., Avol, E., Peters, J. M., \& Gilliland, F. D. (2007). Relationship between air pollution, lung function and asthma in adolescents. Thorax, 62(11), 957-963. DOI: 10.1136/thx.2007.078964

Kubota, T., Miura, M., Tominaga, Y., \& Mochida, A. (2008). Wind tunnel tests on the relationship between building density and pedestrian-level wind velocity: Development of guidelines for realizing acceptable wind environment in residential neighborhoods. Building and Environment, 43, 1699-1708. DOI: 10.1016/j.buildenv.2007.10.015

Li, H., Guo, B., Han, M. F., Tian, M., \& Zhang, J. (2015). Particulate matters pollution characteristic and the correlation between PM (PM2.5, PM10) and meteorological factors during the summer in Shijiazhuang. Journal of Environmental Protection, 6, 457-463. DOI: 10.4236/jep.2015.65044

Moogk-Soulis, C. (2002, October). Schoolyard Heat Islands: A Case Study in Waterloo, Ontario. Technical Aids Consulting Services, 5th Canadian Urban Forest Conference, York, Ontario

Moonen, P., Dorer, V., \& Carmeliet, J. (2011). Evaluation of the ventilation potential of courtyards and urban street canyons using RANS and LES. Journal of Wind Engineering and Industrial Aerodynamics, 99(4), 414-423. DOI: 10.1016/j.jweia.2010.12.012 Milosević, D. D., Bajsanski, I. V., \& Savic, S. M. (2017). Influence of changing trees locations on thermal comfort on street parking lot and footways. Urban forestry \& urban greening, 23, 113-124. DOI: 10.1016/j. ufug.2017.03.011

Ng, E. (2009) Policies and technical guidelines for urban planning of high-density cities: air ventilation assessment (AVA) of Hong Kong. Building and Environment, 44(7), 1478-1488. DOI: 10.1016/j.buildenv.2008.06.013

Niu, J. L., Liu, J. L., Lee, T. C., Lin, Z., Mak, C., Tse, K. T., Tang, B. S., \& Kwok, K. C. S. (2015). A new method to assess spatial variations of outdoor thermal comfort: Onsite monitoring results and implications for precinct planning. Building \& Environment, 91, 263-270. DOI: 10.1016/j.buildenv.2015.02.017

Oke, T. R. (1973). City size and the urban heat island. Atmospheric Environment, 7(8), 769-779. DOI: 10.1016/0004-6981(73)90140-6

Oke, T. R. (1988). Street design and urban canopy layer climate. Energy and Buildings, 11(1-3), 103-113. DOI: 10.1016/0378-7788(88)90026-6

Perera, F. P. (2008). Children are likely to suffer most from our fossil fuel addiction. Environmental Health Perspectives, 116(8), 987-990. DOI: 10.1289/ ehp.11173

Vanos, J. K. (2015). Children's health and vulnerability in outdoor microclimates: A comprehensive review. Environment International, 76, 1-15. DOI: 10.1016/j. envint.2014.11.016

Vitruvius Pollio, M., Sangallo, G., \& Rowland, I. (2003). Ten books on architecture. Roma: Edizione dell'Elefante.

Yang, J. Y., Sun, X., \& Shi, X. (2016). 城市中心热环境 与空间形态耦合机理及优化设计 [Coupling mechanism between thermal environment and space form and optimization design in city center]. Nanjing: Southeast University Press.

Yuan, C., \& Ng, E. (2012). Building porosity for better urban ventilation in high-density cities: A computational parametric study. Building and Environment, 50: 176-189. DOI: 10.1016/j.buildenv.2011.10.023 